\title{
Efisiensi Teknis Usaha Tani Padi Organik Lahan Sawah Tadah Hujan di Kabupaten Tanggamus Provinsi Lampung
}

\section{Technical Efficiency of Organic Rice Farming In Tanggamus Regency Lampung Province}

\author{
Ktut Murniati ${ }^{1}$, Jangkung Handoyo Mulyo ${ }^{2}$, Irham ${ }^{2}$, dan Slamet Hartono ${ }^{2}$ \\ 1. Mahasiswa Program Doktor Fakultas Pertanian Universitas Gadjah Mada \\ 2. Dosen Fakultas Pertanian dan Program Pascasarjana Universitas Gadjah Mada
}

\begin{abstract}
Research on technical efficiency of organic rice farming was conducted in Tampang Tua Vallage, Pematang Sawa District,Tanggamus Regency, Lampung Province. by using the respondents were 60 people taken by the census of the entire organic rice farmers. The aim of this research to analyze technical efficiency, factors influencing technical efficiency, and source of technical inefficiency of rainfed farm organic rice. Technical efficiency is measured by using frontier production function and is istimated using MLE method with Frontier 4.1c computer program. Estimation source of technical inefficiency applies linear regression model that approach simultaneously using frontier production function. The research result indicates that most variables are significant and have expected signs, except for organik solid feltilizer has not significant. The research olso find that the level of technical efficiency varies from 0.423 to 0.999 with the average of 836. Furthermore, variables of farmers education levels, farm organic rice experience, age of the farmers, frekuency of farmers agricultural extentions, and farmer perception on climate change are influencing to reduce technical inefficiency.
\end{abstract}

Keywords: technical efficiency, organic rice, and rainfed paddy field

Diterima: 19-05-2013, disetujui: 17-01-2014

\section{PENDAHULUAN}

Sektor pertanian adalah sektor yang paling berdampak dengan adanya perubahan iklim, akibat bergesernya musim dan berubahnya pola curah hujan. Meningkatnya temperatur akan berdampak terhadap percepatan penguapan, baik dari tanah maupun tanaman, sehingga tanaman akan rentan terhadap kekurangan air yang pada akhirnya akan menurunkan hasil, bahkan sampai pada gagal panen.

Laboratorium Iklim di Institut Pertanian Bogor menyatakan bahwa selama kurun waktu 19811990, setiap kabupaten di Indonesia setiap tahunnya mengalami penurunan produksi padi 100.000 ton; dan pada kurun waktu 1992-2000, jumlah penurunan ini meningkat menjadi 300.000 ton (UNDP Indonesia, 2007).

Perubahan iklim merupakan proses alami yang bersifat tren yang terus menerus dalam jangka panjang. Oleh karena itu diperlukan suatu strategi untuk antisipasi dan penyiapan adaptasi dalam rangka menghadapi perubahan iklim dan mengembangkan pertanian yang tahan terhadap perubahan 
iklim. Di samping itu perlu adanya persepsi yang sama tentang perubahan iklim diantara berbagai kalangan seperti ilmuwan/peneliti, dengan pemangku kebijakan, penyuluh, dan petani (Surmaini et al., 2011).

Dalam rangka mengantisipasi dampak perubahan iklim, maka diperlukan adanya strategi antisipasi yaitu mitigasi dan adaptasi. Menurut Surmaini et al. (2011), teknologi mitigasi untuk mengurangi emisi GRK dari lahan pertanian antara lain adalah penggunaan varitas rendah emisi serta teknologi pengelolaan air dan tanah. Sedangkan teknologi adaptasi bertujuan untuk melakukan penyesuaian terhadap perubahan iklim untuk mengurangi resiko kegagalan produksi pertanian. Teknologi adaptasi meliputi penyesuaian waktu tanam, penggunaan varietas unggul tahan kekeringan, rendaman, dan salinitas serta pengembangan teknologi pengelolaan air.

Salah satu teknologi mitigasi dan adaptasi yang dilakukan sektor pertanian dalam menghadapi perubahan iklim adalah penerapan pertanian organik (FAO, 2010). Pertanian organik memancarkan tingkat emisi gas rumah kaca (GRK) yang jauh lebih rendah dan cepat, terjangkau dan efektif mengaramkan karbon ke dalam tanah. Pertanian Organik mengurangi gas rumah kaca terutama nitro oksida, karena tidak menggunakan pupuk nitrogen kimia dan kehilangan nutrisi dapat diminimalkan. Selain itu, pertanian organik membuat lahan dan manusia lebih tahan terhadap perubahan iklim, terutama karena airnya efisien, tahan terhadap cuaca ekstrim dan resiko kegagalan panen yang lebih rendah. (Purwati, 2010). Di Indonesia munculnya pertanian organik didorong oleh kesadaran manusia untuk mengkonsumsi produk pertanian bebas residu pestisida dan untuk menjaga kelestarian lingkungan (Andoko, 2004).

Dalam rangka mengatasi dampak perubahan iklim, petani diharapkan mampu beradaptasi dengan adanya perubahan iklim dalam berusahatani. Untuk dapat beradaptasi terhadap perubahan iklim, petani harus memiliki pengetahuan dan informasi yang cukup serta persepsi yang baik tentang; perubahan iklim,,varitas yang harus ditanam, pola tanam yang harus diterapkan, manajemen pengairan, dan waktu tanam yang tepat. Apabila petani telah memiliki pengetahuan yang cukup tentang perubahan iklim dan bagaimana cara beradaptasi, maka diharapkan petani mampu mengelola usaha taninya dengan baik sehingga tujuan usaha tani yaitu meningkatkan produksi dan pendapatan dapat tercapai. Untuk dapat meningkatkan produksi, petani sebagai pengelola usaha tani harus memahami dan mampu mengaplikasikan faktor-faktor produksinya dengan baik, bila tidak maka peningkatan produksi tidak akan tercapai. Oleh karena itu, pengalokasian penggunaan faktor-faktor produksi yang efisien dan efektif, serta mampu beradaptasi dengan perubahan iklim sangat menentukan tercapainya efisiensi usahatani.

Berdasarkan Uraian di atas, maka tujuan penelitian ini adalah untuk menganalisis: (1) efisiensi teknis usahatani padi organik, (2) faktor -faktor yang mempengaruhi efisiensi taknis, dan (3) sumber inefisiensi teknis usahatani padi organik lahan sawah tadah hujan di Kabupaten Tanggamus Provinsi Lampung.

\section{METODE}

\section{Lokasi , Responden dan Waktu Penelitian}

Lokasi penelitian dipilih secara sengaja yaitu di Kabupaten Tanggamus, Kecamtanan Pematang Sawa, Pekon Tampang Tua, dengan pertimbangan bahwa di daerah ini merupakan sentra produksi padi organik yang telah mendapatkan sertifikasi dari Indonesian Organic Farming Certification (INOFICE) di Provinsi Lampung dan pernah mengalami kekeringan akibat perubahan iklim tahun 
Ktut Murniati dkk; Efisiensi Teknis Usahatani Padi Organik Lahan Sawah Tadah Hujan...

2012. Penentuan sampel dilakukan secara sensus yaitu mengambil seluruh petani yang mengusahakan padi organik di Pekon Tampang Tua yang berjumlah 60 orang petani. Waktu pengambilan data dilakukan bulan Februari-Maret 2013.

\section{Analisis Data}

Untuk menganalisis efisiensi teknis usahatani padi organik digunakan analisis frontier, atau metode stochastic production frontier (SPF). Fungsi ini pertanma kali diperkenalkan oleh Aigner et al. (1977); serta Meeusen dan Van Den Broek (1977). Pengembangan pada tahun-tahun berikutnya banyak dilakukan seperti oleh Battase dan Coelli $(1992,1995)$.

Model persamaan yang digunakan untuk menduga parameter estimasi dari fungsi produksi Cobb-Douglas dengan pendekatan stochastic frontier dalam penelitian ini adalah sebagi berikut:

$$
\begin{aligned}
\operatorname{Ln} y= & \alpha_{o}+\ln \beta_{1} X_{1}+\beta_{2} \ln X_{2}+\beta_{3} \ln X_{3}+\beta_{4} \ln X_{4}+\beta_{5} \ln X_{5}+\beta_{6} \ln X_{6} \\
& +\beta_{7} \ln X_{7}+\left(v_{i}-u_{i}\right) \ldots \ldots \ldots \ldots \ldots \ldots \ldots \ldots \ldots \ldots \ldots \ldots \ldots \ldots \ldots \ldots
\end{aligned}
$$

Keterangan:

$\mathrm{Y}=$ produktivitas padi sawah organik $(\mathrm{kg})$

$\alpha=$ intersept

$\beta=$ koefisien regresi (koefisien parameter yang ditaksir) ( $\mathrm{i}=1 \mathrm{~s} / \mathrm{d} 7$ )

$\mathrm{X}_{1}=$ strategi adaptasi/antisipasi dampak perubahan iklim dalam berusahatani padi sawah (jumlah)

$\mathrm{X}_{2}=$ tenaga kerja luar keluarga $(\mathrm{HOK})$

$\mathrm{X}_{3}=$ tenaga kerja dalam keluarga $(\mathrm{HOK})$

$\mathrm{X}_{4}=$ benih $(\mathrm{kg})$

$\mathrm{X}_{5}=$ pupuk organik padat $(\mathrm{kg})$

$\mathrm{X}_{6}=$ pupuk organik cair (ltr)

$\mathrm{X}_{7}=$ pupuk kandang $(\mathrm{kg})$

$\mathrm{v}_{\mathrm{i}}-\mathrm{u}_{\mathrm{i}}=$ error term $\left(\mathrm{u}_{\mathrm{i}}\right)$ efek inefisiensi dalam model.

Model stochastic frontier disebut juga dengan model composed error karena error term terdiri dari dua komponen yaitu:

$$
\mathrm{Ei}=\mathrm{v}_{\mathrm{i}}-\mathrm{u}_{\mathrm{i}} \quad \mathrm{I}=1,2, \ldots, \mathrm{n}
$$

Komponen error yang pertama $v_{i}$ adalah error karena faktor ekternal yang diasumsikan mengikuti distribusai normal simetris $\left(\mathrm{v}_{\mathrm{i}} \approx 0, \sigma_{\mathrm{v}}{ }^{2}\right)$. Sedangkan komponen error yang kedua $\mathrm{u}$ adalah error karena faktor internal yang dapat dikendalikan oleh petani dan menggambarkan kemampuan manajerial petani. Komponen ini diasumsikan berdistribusi asimetris $\left(\mathrm{u}_{\mathrm{i}}>0\right)$ atau setengah distribusi niormal $\left(\mathrm{u}_{\mathrm{i}} \approx \mathrm{N}\left(0, \sigma_{\mathrm{u}}^{2}\right)\right.$. Apabila proses produksi sepenuhnya efisien, maka produksi yang dicapai sama dengan potensinya atau $\mathrm{u}_{\mathrm{i}}=0$, sebaliknya apabila produksi yang dicapai di bawah potensinya, maka $u_{i}>0$.

Rumus yang digunakan untuk menentukan nilai efisiensi teknis didasarkan pada pendapat Jondrow, et al (1982), mengestimasi tingkat efisiensi teknis (technical efficiency, TE) sebagai berikut:

$$
\begin{aligned}
& \mathrm{TE}=\exp \left(-\mathrm{E}\left[\mathrm{u}_{\mathrm{i}} / \mathrm{Ei}\right]\right) \\
& \text { dengan } \mathrm{E}\left[\mathrm{u}_{\mathrm{i}} / \mathrm{Ei}\right]=\frac{\sigma_{\mathrm{u \sigma}_{v}}}{\sigma}\left[\frac{f\left(\frac{\mathrm{EV}}{\sigma}\right)}{1-F\left(\frac{E \mathrm{i}}{\sigma}\right)}-\left(\frac{\mathrm{E}_{\mathrm{i} \lambda}}{\sigma}\right)\right]
\end{aligned}
$$

dimana $\lambda=\sigma_{\mathrm{u}} / \sigma_{\mathrm{v}}, \sigma^{2}=\sigma_{\mathrm{u}}{ }^{2}+\sigma_{\mathrm{v}}{ }^{2}$. Sedangkan $\mathrm{f}$ dan F masing masing menunjukkan fungsi densitas standar normal dan fungsi distribusi kumulatif standart normal yang dihitung dari $€ i \lambda$. Untuk melihat 
pengaruh faktor-faktor penentu tingkat inefisiensi teknis digunakan suatu model regresi linear berganda dengan formula sebagai berikut:

$$
\mathrm{U}_{\mathrm{i}}=\delta_{\mathrm{o}}+\delta_{1} \mathrm{z}_{1}+\delta_{2} \mathrm{z}_{2}+\delta_{3} \mathrm{z}_{3}+\delta_{4} \mathrm{z}_{4}+\delta_{5} \mathrm{z}_{5}
$$

Keterangan: $U_{i}$ adalah inefisiensi produksi yang dicapai oleh petani ke-i, sementara $z_{I}-z_{5}$ berturut-turut adalah pendidikan petani, pengalaman berusahatani, usia petani, frekuensi mengikuti penyuluhan, dan persepsi petani tentang perubahan iklim.

Pendugaan parameter yang tak bias adalah menggunakan metode Maximum Likelihood Estimator (MLE). Agar konsisten maka pendugaan parameter fungsi produksi dan "inefficiency function" dilakukan secara simultan dengan program FRONTIER version 4.1 (Coelli, 1995) .

\section{HASIL DAN PEMBAHASAN}

\section{Karakeristik Petani}

Berdasarkan hasil penelitian, umur petani responden berkisar antara 20 sampai 77 tahun dengan rata-rata umur petani padi organik adalah 45 tahun. Tingkat pendidikan petani responden sebagian besar tamat Sekolah Dasar (SD) yaitu 50\%, 28,33\% tidak tamat SD, 16,67\% tamat SLTP, dan sisanya $5 \%$ tamat SLTA dan perguruan tinggi. Pengalaman petani berusahatani padi organik relatif masih baru yaitu berkisar antara 1 sampai 10 tahun dengan rata -rata pengalaman petani adalah 4 tahun. Jumlah anggota keluarga petani responden berkisar 2 sampai dengan 8 orang, dengan rata-rata anggota keluarga masing-masing 5 orang.

Petani merupakan pekerjaan pokok atau utama yang dilakukan petani untuk memenuhi kebutuhan hidup petani. Di Pekon Tampang Tua sebagian besar yaitu 44 orang (73,33\%), menjadikan petani sebagai satu-satunya pekerjaan dan sisanya $(26,67 \%)$ memiliki pekerjaan sampingan seperti PNS, tukang, ojek, berdagang, buruh, dan nelayan. Luas lahan sawah yang diusahakan petani bervariasi dari 0,12 hektar sampai 1,5 hektar, dengan rata-rata luas lahan usahatani padi petani adalah 0,59 ha.

\section{Deskripsi statistik variabel}

Deskripsi statistik seluruh variabel yang digunakan untuk menduga fungsi produksi stokhastik prontier disajikan pada tabel 1 . Tabel 1 menunjukkan bahwa rata-rata produktivitas padi organik per hektar pada musim hujan (MH) sebesar 5586,4 kg gabah kering panen (GKP. Hal ini menunjukkan bahwa rata-rata produktivitas padi organik yang dicapai petani lebih besar dibandingkan rata-rata produktivitas padi di Kabupaten Tanggamus (5,12 ton/ha). Rata-rata strategi adaptasi/antisipasi yang dilakukan petani terhadap dampak perubahan iklim sebanyak 10 strategi, penggunaan tenaga kerja luar keluarga rata-rata sebesar 46,8 HKP, sedangkan penggunaan tenaga kerja dalam keluarga rata-rata sebesar 79,0 HKP . Selanjutnya rata-rata penggunaan benih sebesar 43,3 kg. Rata penggunaan pupuk organik padat sebesar $225,1 \mathrm{~kg}$, penggunaan pupuk organik cair rata-rata sebesar 9,5 liter. Sementara penggunaan pupuk kandang rata-rata sebesar 498,3 kg. 
Ktut Murniati dkk; Efisiensi Teknis Usahatani Padi Organik Lahan Sawah Tadah Hujan...

Tabel 1. Deskripsi variabel usaha tani padi organik lahan sawah tadah hujan pada musim hujan dan musim kemarau per hektar di Kecamatan Pematang Sawa Kabupaten Tanggamus 2012

\begin{tabular}{lcccc}
\hline \multirow{2}{*}{ Variabel } & \multicolumn{3}{c}{ Musim hujan } \\
\cline { 2 - 5 } & $\mathrm{N}$ & Rerata & Min. & Maks. \\
\hline Produksi (Kg) & 60 & 5586,4 & 2165,7 & 8200,0 \\
Strategi Adaptasi (jml) & 60 & 10 & 3 & 13 \\
TKLK (HKP) & 60 & 46,8 & 3,3 & 104,6 \\
TKDL (HKP) & 60 & 79,0 & 43,2 & 123,36 \\
Benih (Kg) & 60 & 43,3 & 20,0 & 70,0 \\
POP (kg) & 60 & 225,1 & 40,0 & 833,0 \\
POC (liter) & 60 & 9,5 & 1,0 & 48,0 \\
P.Kandang (Kg) & 60 & 498,3 & 6,0 & 2400,0 \\
\hline
\end{tabular}

Sumber:Analisis Data Primer, 2012

\section{Efisiensi Teknis Produksi Padi Organik}

Hasil estimasi fungsi produksi stokhastik frontier menggunakan MLE pada MH (Tabel 2) menggungkapkan bahwa faktor-faktor produksi seperti strategi adaptasi/antisipasi petani terhadap dampak perubahan iklim, tenaga kerja luar keluarga, tenaga kerja dalam, penggunaan benih, penggunaan pupuk organik cair, dan penggunan pupuk kandang mempunyai koefisien positif dan berpengaruh nyata pada $\alpha=0.01$ dan $\alpha=0.05$ terhadap produksi padi organik. Sedangkan pupuk organik padat dimasukkan dalam model, tetapi tidak berpengaruh nyata terhadap produksi.

Koefisien dari strategi adaptasi/antisipasi petani terhadap dampak perubahan iklim sebesar 0,097 berarti bahwa peningkatan jumlah strategi adaptasi yang dilaksanakan untuk mengantisipasi dampak perubahnan iklim $1 \%$ akan meningkatkan produksi sebesar 0,097 . Koefisien penggunaan tenaga kerja luar keluarga sebesar 0,023 berarti bahwa peningkatan $1 \%$ tenaga kerja luar keluarga akan meningkatkan produksi sebesar $0,023 \%$

Tabel 2. Hasil Estimasi MLE fungsi produksi stokhastik frontier tahun 2012

\begin{tabular}{lcccc}
\hline Nama parameter & Parameter & Coefficient & Standard-error & t-ratio \\
\hline Intercept & $\beta \mathrm{o}$ & 6,7201114 & 0,14316057 & $46,941077^{* * *}$ \\
Strategi adaptasi & $\beta 1$ & 0,0976258 & 0,01547620 & $63,081306^{* * * *}$ \\
Tk.Luar Keluarga & $\beta 2$ & 0,0232087 & 0,00692692 & $3,350508^{* * * *}$ \\
Tk.Dalam Keluarga & $\beta 3$ & 0,1692811 & 0,04705033 & $3,597872^{* * * *}$ \\
Benih & $\beta 4$ & 0,1913350 & 0,01391848 & $13,746828^{* * *}$ \\
POP & $\beta 5$ & 0,0043528 & 0,01176312 & $0,370040^{\mathrm{ns}}$ \\
POC & $\beta 6$ & 0,0184699 & 0,01075107 & $1,717963^{* * *}$ \\
Pupuk Kandang & $\beta 7$ & 0,0456154 & 0,00985251 & $4,629828^{* * * *}$ \\
Sigma-squared & $\sigma^{2}$ & 0,1104739 & 0,00784609 & $14,080113^{* * *}$ \\
Gamma & $\Upsilon$ & 0,999999 & 0,00002528 & $39551,376^{* * * *}$ \\
\hline Strat
\end{tabular}

Sumber: Analisis Data Primer, 2013

Keterangan: $* * *$ : signifikan pada $\quad \alpha=0,01(\mathrm{t}$ tabel $=2,6737)$

**: signifikan pada $\alpha=0,05(\mathrm{t}$ tabel $=2,0066)$

ns: tidak signifikan

Koefisien penggunaan tenaga kerja dalam keluarga sebesar 0,169 berarti bahwa peningkatan $1 \%$ tenaga kerja dalm keluarga akan meningkatkan produksi sebesar 0,169 \%. Koefisien benih sebesar 0,191 berarti bahwa peningkatan penggunaan benih sebesar $1 \%$, akan meningkatkan produksi sebesar $0,191 \%$. Koefisien penggunaan pupuk organik cair sebesar 0,018 berarti bahwa peningkatan penggunaan pupuk organik cair sebesar $1 \%$, akan meningkatkan produksi sebesar 0,018 \%. Koefisien penggunaan pupuk kandang sebesar 0,046 berarti bahwa peningkatan penggunaan pupuk organik cair sebesar $1 \%$, akan meningkatkan produksi sebesar $0,046 \%$. Nilai sigma-squared sebesar 0,11047 dan 
signifikan pada $\alpha=0,01$ berarti bahwa jumlah produksi padi organik yang dihasilkan petani di Kecamatan Pematang Sawa mempunyai variasi yang sama. Sementara itu, nilai gamma yang dihasilkan dari estimasi ekonometrika sebesar 0,9999 dan nyata pada $\alpha=0,01$. Hal ini menunjukkan bahwa $99,99 \%$ tingkat variasi jumlah produksi padi organik yang dihasilkan petani di Kecamatan Pematang Sawa disebabkan oleh adanya faktor inefisiensi dalam proses produksi.

Tingkat efisiensi teknis usahatani padi organik lahan sawah tadah hujan pada musim hujan di daerah penelitian paling rendah adalah 0,42331271 dan paling tinggi adalah 0,99990999 , dengan ratarata tingkat efisiensi teknis usahatani padi organik lahan sawah tadah hujan sebesar 0,83610907. Ratarata tingkat efisiensi teknis sebesar 0,83610907, berarti bahwa secara rata-rata usahatani padi organik yang dilakukan petani di daerah penelitian pada musim hujan secara teknis sudah efisien (Coelli, 1998) atau rata-rata petani telah mencapai $83,61 \%$ dari potensial produksi yang diperoleh dari kombinasi input produksi yang dikorbankan. Namun demikian berarti juga bahwa masih ada peluang bagi petani untuk meningkatkan produksi padi organik di daerah penelitian sebesar 16,39\%. Sebaran tingkat efisiensi teknis usahatani padi orgaik disajikan pada tabel 3.

Tabel 3. Sebaran petani berdasarkan tingkat efisiensi teknis usahatani padi organik pada musim hujan, 2012

\begin{tabular}{cc}
\hline Tingkat Efisiensi & Jumlah petani \\
\hline & 1 \\
0,50 & 2 \\
$0,51-0,70$ & 6 \\
$0,71-0,80$ & 12 \\
$0,81-0,90$ & 17 \\
$>0,90$ & 23 \\
\hline Rerata $=0,8361$ & 60
\end{tabular}

Sumber: Analisis Data Primer, 2013

Berdasarkan Taberl 3, bahwa sebagian besar petani (23 petani) padi organik di Kecamatan Pematang Sawa telah mencapai efisiensi teknis lebih tinggi dari 0,90. Perbedaan tingkat efisiensi teknis yang dicapai petani mengindikasikan bahwa tingkat penguasaan dan penerapan teknologi yang berbeda-beda. Tingkat penguasaan teknologi yang berbeda-beda dari petani disebabkan oleh faktor intern dalam diri petani seperti pendidikan, umur, pengalaman berusahatani, frekuensi mengikuti penyuluhan dan faktor ektern seperti musim. Perbedaan tingkat efisiensi teknis yang dicapai petani disamping disebabkan oleh faktor internal dan ekternal petani juga disebabkan oleh perbedaan strategi adaptasi yang dilakukan petani terhadap dampak perubahan iklim dan persepsi petani yang baik tentang perubahan iklim.

Hasil estimasi fungsi inefisiensi teknis (Tabel 4), menunjukkan bahwa seluruh variabel penentu inefisiensi yang dimasukkan berpengaruh yaitu variabel pendidikan, pengalaman berusaha tani, umur, frekuensi mengikuti penyuluhan, dan variabel persepsi petani tentang perubahan iklim.

Koefisien pendidikan petani responden terhadap tingkat inefisiensi teknis adalah negatif (24922) dan signifikan secara statistik pada taraf $\alpha=0,01$. Hal ini berarti meningkatnya tingkat pendidikan akan menurunkan tingkat inefisiensi teknisnya, atau dengan kata lain meningkatkan efisiensi teknis. Koefisien variabel pengalaman dalam berusahatani padi organik terhadap tingkat inefisiensi teknis bernilai negatif $(-0,07668)$ dan signifikan pada taraf $\alpha=0,10$. Hal ini menunjukkan bahwa semakin lama pengalaman petani berusahatani padi organik, maka semakin efisien dalam mengelola usaha taninya, karena semakin lama berusahtani, petani semakin memiliki pengetahuan dalam mengelola usahatani padi organik dengan baik. 
Ktut Murniati dkk; Efisiensi Teknis Usahatani Padi Organik Lahan Sawah Tadah Hujan...

Tabel.4. Estimasi fungsi inefisiensi teknis usahatani padi organik

\begin{tabular}{llccc}
\hline Variabel & parameter & koefisien & Strandar error & t-ratio \\
\hline Itersept & $\delta_{\mathrm{o}}$ & 8,10398 & 0,645499 & $12,55458^{* * * * *}$ \\
Pendidikan & $\delta_{1}$ & $-0,24922$ & 0,070572 & $3,53147^{* * * *}$ \\
Pengalaman berusahatani & $\delta_{2}$ & $-0,07668$ & 0,047453 & $1,61606^{* * *}$ \\
Umur & $\delta_{3}$ & $-0,71960$ & 0,071442 & $10,07249^{* * * * *}$ \\
Frekuensi Penyuluhan & $\delta_{4}$ & $-0,46000$ & 0,008443 & $54,48411^{* * * *}$ \\
Persepsi & $\delta_{5}$ & $-0,98479$ & 0,281614 & $3,49697^{* * * *}$ \\
Sigma-squred & & 0,110474 & 0,007846 & $14,08011^{* * * *}$ \\
Gamma & & 0,999999 & 0,000025 & $39551,376^{* * *}$ \\
\hline
\end{tabular}

Sumber: Analisis Data Primer, 2013

Keterangan: $* * *$ : signifikan pada $\alpha=0,01(\mathrm{t}$ tabel $=2,6737)$

$* *$ : signifikan pada $\alpha=0,05(\mathrm{t}$ tabel $=2,0066)$

*: Signifikan pada $\alpha=0,10(\mathrm{t}$ tabel $=1,6026)$

ns: tidak signifikan

Koefisien variabel umur terhadap tingkat inefisiensi teknis bernilai negatif $(-0,71960)$ dan signifikan pada taraf $\alpha=0,01$. Hal ini menunjukkan bahwa semakin tua umur petani akan menurunkan tingkat inefisiensi teknis, atau dengan kata lain semakin tua umur petani semakin efisien usaha tani yang dikelola. Hal ini sesuai dengan kondisi dilapangan bahwa rata-rata usia petani adalah 45 tahun.

\section{KESIMPULAN}

Hasil penelitian menunjukkan bahwa variabel strategi adaptasi/antisipasi petani terhadap dampak perubahan iklim, tenaga kerja luar keluarga, tenaga kerja dalam keluarga, benih, penggunaan pupuk organik cair, dan penggunaan pupuk kandang berpengaruh terhadap produktivitas padi organik. Sedangkan penggunaan pupuk organik padat tidak berpengaruh nyata terhadap produktivitas padi organik. Tingkat efisiensi teknis yang dicapai petani responden bervariasi dari 0,423-0,999, dengan rata-rata 0,836 , yang berarti usaha tani padi organik yang dilakukan petani di lahan sawah tadah hujan sudah efisien secara teknis, namun masih memungkinkan petani untuk menigkatkan produksinya sebesar16,39\% melalui peningkatan penerapan manajemen yang terbaik. Penelitian ini juga menemukan bahwa variabel pendidikan, pengalaman berusahatani padi organik, umur, frekuensi mengikuti penyuluhan, dan persepsi petani tentang perubahan iklim berpengaruh menurunkan inefisiensi teknis.

\section{IMPLIKASI KEBIJAKAN}

Implikasi kebijakan dari hasil temuan-temuan penelitian ini adalah upaya meningkatkan efisiensi teknis melalui pemberian informasi iklim yang tepat dan kontinyu, sehingga petani mampu mengadaptasi/mengantisipasi dampak perubahan iklim dengan baik. Di samping itu perlu adanya penyuluhan tentang perubahan iklim sehingga petani memiliki persepsi yang baik tentang perubahan iklim sehingga petani mampu melakukan penyesuaian-penyesuaian dengan adanya perubahan iklim dalam berusahatani padi. 


\section{DAFTAR PUSTAKA}

Aigner, D.J, C.A.K.Lovell and P. Schmidt. 1977. Formulation and Estimation of Stochastic Frontier Production Function Models. Journal of Econometrics, 6(1):21-37.

Andoko, A. 2004. Budidaya Padi Secara Organik. Penebar Swadaya. Jakarta. 92

Bettese, G.E. and Coelli, T.J. 1992. "Frontier Production. Technical Efficiency and Panel Data:: With Applications to Paddy Farmers in India". Journal of Productivity Analysis, 3 : 153-169..

Battese, G.E. and T.J. Coelli. 1995. A Model For Technical Inefficiency Effects In a Stochastic Frontier Production Function Model For Panel Data. Empirical Economics. 20 (2): 325-332.

Coelli, T.J. 1995. A Guide to Frontier, Version 4.1: A Computer program for Stochastic Frontier Production and Cost Function Estimation. Departement of econometrics, University og New England, Armidale, NSW, Australia.

Coelli, T.J., D.S.P. Rao and G.E.Battese. 1998. An Introduction to Efficiency and Productivity Analysis, Kluwer-Nijhoff, Boston.

FAO. 2010. Facific Food Securlty Toolkit: Building Resilience To Climat Change. Root Crop and Fishery Production. Food and Agriculture Organization of United Nation. Rome. 2010.

Jondrow, J., C.A.K Lovell, LS. Matrov and P Schmidt. 1982. On Estimation of Technical Inefficiency in the Stochastic Frontier Production Function Model. Journal of Econometrics, 19, 233-238.

Meeusem, W and J. Van den Broek. 1977. Efficiency Estimation from Cobb-Douglas Production Function with Compossed Error. International Economic Review 18 (2): 435-444.

Purwati, Ani. 2010. Pertanian Organik Mengatasi Perubahan Iklim dan Tingkat Ketahanan Pangan. File://BERITABUMI.com.htm. Diakses tanggal 9 oktober 2012.

Surmaini, E., E. Runtunuwu. dan I Las. 2011. Upaya Sektor Pertanian Dalam Menghadapi Perubahan Iklim. Jurnal Litbang Pertanian. 30(1); 1-7.

UNDP Indonesia. 2007. Sisi Lain Perubahan Iklim: Mengapa Indonesia harus beradaptasi untuk melindungi rakyat miskinnya. 20 . pp. 